\title{
The impact of COVID-19 and social avoidance in urgent and emergency surgeries - will a delay in diagnosis result in perioperative complications?
}

\author{
Rodrigo Piltcher-da-Silva ${ }^{1 *} \odot$, Tiago Lima Castro ${ }^{\oplus}$, Artur Gehres Trapp ${ }^{\circledR}$, Simoni Bohnenberger ${ }^{1} \odot$, \\ Eduardo Castelli Kroth ${ }^{1} \odot$, Jorge Armando Reyes Pinto ${ }^{1} \odot$, Caroline Grehs ${ }^{1} \odot$,

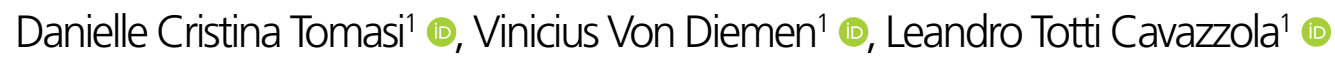

\section{SUMMARY}

OBJECTIVE: The sudden COVID-19 outbreak has changed our health system. Physicians had to face the challenge of treating a large number of critically ill patients with a new disease and also maintain the essential healthcare services functioning properly. To prevent disease dissemination, authorities instructed people to stay at home and seek medical care only if they experienced respiratory distress. However, there are concerns those patients did not seek necessary health care because of these orientations. This study aims to see how the pandemic has influenced the severity of the disease, complication, and mortality of patients undergoing emergency cholecystectomy and appendectomy.

METHODS: Retrospective review of medical records of patients admitted to the emergency department and undergoing to cholecystectomy and appendicectomy in the periods from March to May 2019 and 2020.

RESULTS: We observed that COVID-19 did not change the severity of presentation or the outcome of patients with gallbladder disease, but caused a $24.2 \%$ increase in the prevalence of complicated appendicitis $(p<0.05)$. However, disagreeing with what was expected, we did not identify a greater number of perioperative complications in patients undergoing an appendectomy.

CONCLUSION: Therefore, it seems that in a university tertiary referral center COVID-19 did not influence the management and outcome of inflammatory diseases treated in the surgical emergency department.

KEYWORDS: COVID-19. Pandemics. Surgery. Emergency. SARS-CoV-2. Appendectomy. Cholecystectomy.

\section{INTRODUCTION}

The COVID-19 outbreak has affected healthcare systems across the world, and Brazil was not an exception - the country was one of the epicenters of the disease for months. In this context, as well as in other services worldwide, we hypothesized an increase in the severity of other pathologies, probably due to the delay in seeking medical care due to the isolation and fear of exposure to the hospital environment ${ }^{1}$. In addition, due to the sharp increase in the demand for medical services, mainly for emergency and intensive care units, the health system was saturated and there was a consequent difficulty in accessing care.

Among the main causes for seeking urgent care and emergency medical care are acute appendicitis (AA) and gallbladder diseases $(\mathrm{GBD})^{2}$, which can serve as a "thermometer" for the emergency surgical service.

Gallbladder lithiasis is a common condition, with a prevalence of $72 \%$ in the literature described in the general population ${ }^{3}$. The most common complication of this pathology is

\footnotetext{
'Universidade Federal do Rio Grande do Sul, Hospital de Clínicas de Porto Alegre, General Surgery Service - Porto Alegre (RS), Brazil.

*Corresponding author: rodrigopiltcher@gmail.com

Conflicts of interest: the authors declare there are no conflicts of interest. Funding: none.

Received on February 16, 2021. Accepted on February 18, 2021.
} 
acute cholecystitis (7-11\%) and typically appears in patients in whom cholelithiasis is symptomatic ${ }^{4}$. The most serious complication in this context is perforation, but it is rare and occurs most commonly in men ${ }^{5}$. In the GBD group, the benefits of early surgery (within 24 to 72 hours of symptoms) have already been well documented in the medical literature ${ }^{6}$, but achieving this "better" treatment during the pandemic may be difficult.

$\mathrm{AA}$ is the most common reason for an urgent abdominal operation, with a lifetime incidence of $7-15 \% \%^{1,2,7,8}$. The risk of complications seems to be directly related to the duration of symptoms, being higher after 36 hours, in addition to being influenced by age and comorbidities ${ }^{7}$.

Thus, we chose to study these pathologies to determine whether there was an impact of COVID-19 on the severity and perioperative complications of patients in the surgical emergency of a university hospital in southern Brazil. We evaluated patients that were not infected with coronavirus but were affected by the impact of social isolation and service saturation, with the hypothesis of an increase in severe cases and a consequent greater number of complications.

\section{METHODS}

Retrospective review of medical records of patients admitted to the emergency department and undergoing laparoscopic cholecystectomy due to cholecystitis or cholelithiasis with refractory pain and laparoscopic or conventional appendectomy for treatment of appendicitis at the Hospital de Clínicas de Porto Alegre from March to May 2019 (our control group, showing how the diseases used to present in previous years) and from March to May 2020 (with the influence of lockdown and social restrictions imposed by the government). The following variables were analyzed: gender, age, time of symptom until medical care, comorbidities, surgical findings, and perioperative complications. The severity of intraoperative findings was assessed using the Parkland scale - for laparoscopic cholecystectomy - and those who underwent appendectomy were divided according to the intraoperative macroscopic findings into uncomplicated AA (catarrhal, phlegmonous, and ulcer-phlegmonous) and complicated AA (suppurative, gangrenous, and perforated). The only exclusion criterion was being under 15 years old at the time of surgery. For statistical analysis, Chi-Square and Mann-Whitney tests were used using SPSS software version 23.0.

\section{RESULTS}

A total of 301 medical records of patients undergoing laparoscopic cholecystectomy and laparoscopic and conventional appendectomy were evaluated. In the period from March to April 2019, a total of 31 surgeries for the treatment of AA and 152 GBD were performed, while for the same period in 2020 , 40 and 78 were performed respectively.

The profile of the patients was similar between the two years: age, comorbidities, and sex remained within the same pattern. For patients with AA in 2019, 17 (54.8\%) were men and the average age of these patients was 31.7 ( \pm 13.4$)$. In 2020, 26 patients $(65 \%)$ were men and the average age was $36.3( \pm 17.1)$. For patients with GBD in 2019, 37 (24.3\%) were men and their average age was $52.1( \pm 15.5)$. In 2020,20 patients $(25.3 \%)$ were men with an average age of $46.4( \pm 17.9)$.

The difference of comorbidities between the groups after controlling for potentially confounding variables such as age, gender, alcoholism, smoking, neoplastic disease, immunosuppression, diabetes, hypertension, renal dysfunction, liver dysfunction, and cardiopulmonary disease in the analysis, was statistically insignificant and the most prevalent being systemic arterial hypertension. The time from symptoms to medical evaluation for GBD was significantly shorter in 2020 ( $\mathrm{p}=0.003$ ), on the other hand, the time from symptoms to medical evaluation for AA did not present significant differences $(\mathrm{p}=0.650)$.

The most prevalent intraoperative findings were Parkland grade 1 to 3 for GBD in both years studied. Complicated AA was found in 50\% of cases in 2020 and only in $25.8 \%$ in 2019, a finding with statistical significance $(\mathrm{p}<0.05)$ (Table 1).

The rates of perioperative complications were 15\% in 2019 and $6.8 \%$ in 2020 after cholecystectomy $(\mathrm{p}=0.153)$ and, in appendectomy, the rate was $25.8 \%$ in 2019 and $12.5 \%$ in $2020(\mathrm{p}=0.259)$. The most prevalent complication was of pulmonary origin in both years for both procedures (Table 2).

Table 1. Severity of intraoperative findings.

\begin{tabular}{l|c|c|c|c}
\multirow{2}{*}{} & \multicolumn{2}{|c|}{ Cholecystectomy } & \multicolumn{2}{c}{ Appendicectomy } \\
\cline { 2 - 5 } & 2019 & 2020 & 2019 & 2020 \\
\hline Uncomplicated (\%) & $127(86.6)$ & $67(85.9)$ & $23(74.2)$ & $20(50)$ \\
\hline Complicated (\%) & $25(16.4)$ & $11(14.1)$ & $8(25.8)$ & $20(50)$ \\
\hline p-value & \multicolumn{2}{|c|}{ Not significant } & \multicolumn{2}{c}{$<0,05$} \\
\hline
\end{tabular}


Regarding the severity of this complication, no significant differences were found in the present study (Table 3 ). The length of hospitalization was an average of 2 days in 2019 and 3 days in 2020 for both procedures $(\mathrm{p}=0.122$ for cholecystectomy and $\mathrm{p}=0.455$ for appendectomy).

\section{DISCUSSION}

In March 2020, the World Health Organization declared the COVID-19 outbreak a global pandemic ${ }^{10}$. During the pandemic, health systems around the world faced the need to reorganize to deal with a new disease and, at the same time, maintain the provision of essential health services. However, due to overcrowding, the risk of system collapse and the need to prioritize care for the most serious patients, some diseases were left in the "background". Patriti et. al. reports that in Italy " $80 \%$ of surgical departments changed their practices" ${ }^{\prime 1}$, this reality was also present in Brazil, causing a greater chance of delay in the diagnosis and surgical procedure of several pathologies.

Government officials advised patients with fever to stay in isolation at home and go to the emergency room only in case they had breathing difficulties. This was of paramount importance for controlling the spread of the disease and reducing the lines in healthcare services. However, some patients did not have a fever due to COVID-19, but due to abdominal inflammatory / infectious disease, which may have worsened the clinical condition before an adequate medical evaluation.

Table 2. Postoperative complications.

\begin{tabular}{l|c|c|c|c|c|c}
\multirow{2}{*}{ Postoperative complications } & \multicolumn{2}{|c|}{ Cholecystectomy } & & \multicolumn{2}{|c}{ Appendicectomy } \\
\cline { 2 - 4 } \cline { 6 - 8 } & 2019 & 2020 & & 2019 & 2020 & \\
\hline Adynamic ileus (\%) & 0 & $1(1.4)$ & NS & $2(6.5)$ & $1(2.5)$ & NS \\
\hline Bruise (\%) & $2(1.3)$ & 0 & NS & 0 & 0 & - \\
\hline Seroma (\%) & $4(2.6)$ & 0 & NS & $3(9.7)$ & $1(2.5)$ & NS \\
\hline Surgical wound infection (\%) & $2(1.3)$ & 0 & NS & $3(9.7)$ & 0 & NS \\
\hline Deep infection (\%) & $3(2.0)$ & 0 & NS & $1(3.2)$ & $1(2.5)$ & NS \\
\hline Aponeurosis dehiscence (\%) & 0 & $1(1.4)$ & NS & 0 & 0 & - \\
\hline Bleeding with transfusion (\%) & $2(1.3)$ & 0 & NS & 0 & 0 & - \\
\hline Pulmonary complication* (\%) & $57(37.5)$ & $3(4.1)$ & p<0.05 & $12(38.7)$ & $1(2.5)$ & p<0.05 \\
\hline Arrhythmia (\%) & $1(0.7)$ & 0 & NS & 0 & 0 & NS \\
\hline Deep vein thrombosis (\%) & 0 & 0 & - & 0 & $1(2.5)$ & NS \\
\hline Stroke (\%) & 0 & 0 & - & 0 & 0 & - \\
\hline Others (\%) & $12(7.9)$ & 0 & NS & $1(3.2)$ & $1(2.5)$ & NS \\
\hline
\end{tabular}

NS: not significant.

Table 3. Severity of complication.

\begin{tabular}{l|c|c|c|c|c|c|c}
\multirow{2}{*}{ Severity of Complication } & \multicolumn{2}{|c|}{ Cholecystectomy } & \multirow{2}{*}{$\mathrm{p}$} & \multicolumn{2}{c|}{ Appendectomy } & \multirow{2}{*}{$\mathrm{p}$} \\
\cline { 2 - 3 } & 2019 & 2020 & & 2019 & 2020 & \\
Hassle free (\%) & $126(82.9)$ & $70(95.9)$ & NS & $24(77.4)$ & $35(87.5)$ & NS \\
\hline Delay of discharge or need for readmission (\%) & $18(11.8)$ & $2(2.7)$ & NS & $6(19.4)$ & $3(7.5)$ & NS \\
\hline New invasive procedure (\%) & $1(0.7)$ & $1(1,4)$ & NS & $1(3.2)$ & 0 & NS \\
\hline ICU readmission (\%) & $4(2.6)$ & 0 & NS & 0 & $2(5.0)$ & NS \\
\hline Death (\%) & $3(2.0)$ & 0 & NS & 0 & 0 & NS \\
\hline
\end{tabular}

NS: not significant. 
Although the number of appendectomies remained similar between the periods analyzed, the number of cholecystectomies was influenced by the pandemic. This fact occurred due to a reduction in the number of cases referred to the service (reference in COVID-19).

In our sample, no statistically significant differences were found in the assessed items (severity of presentation, perioperative complications, length of hospitalization) in the period of laparoscopic cholecystectomies. There was no delay in the diagnosis of acute conditions, although the diagnosis time was significantly shorter. This fact can be easily explained by the inclusion of pathologies without inflammation, such as refractory symptomatic cholelithiasis and by having maintained the procedures in patients with comorbidities, which would not be recommended to postpone until after the pandemic. In addition, fear of coronavirus infection and misinformation left the general population more aware of any symptoms, inhibiting home management with symptomatic patients in respiratory conditions or abdominal pain, mainly. In addition to this, even though it is difficult to prove, the dietary change due to long-term homestay may have contributed to an increase in cases of symptomatic cholelithiasis and acute cholecystitis in patients who previously waited for elective surgery.

For intraoperative findings in laparoscopic cholecystectomy, our numbers are compatible with those described in the literature (about $65 \%$ in mild degree, 30\% in moderate degree and $5 \%$ in severe degree $)^{9}$. The reported incidence of trans-operative complications related to the gallbladder is $10-40 \%^{12}$, this number is lower than described in the literature $(14.5 \%$ in 2019 and $6.8 \%$ in 2020).

The relationship between duration of symptoms and the risk of progression to complicated AA has been demonstrated in several studies ${ }^{2,13}$. AA has a $5 \%$ increase in the risk of perforation every 12 hours after 36 hours, especially in young patients and those over the age of $50^{1,13}$. As complicated acute appendicitis is an independent risk factor for the formation of surgical site abscess after laparoscopic appendectomy and mortality is $<0.1 \%$ in uncomplicated AA and reaches $5 \%$ in the case of perforation, early diagnosis is of great importance ${ }^{1,2,14}$. In the present study, complicated AA was diagnosed in more cases during the pandemic, however, the time spent before seeking medical care and the execution of treatment were similar. In addition, even with a percentage increase of $24.2 \%$ in severe cases $(\mathrm{p}<0.05)$, there was no change in the incidence of perioperative complications, mortality or increased length of hospital stay compared to the previous year, as shown in the results.
During the peak of COVID-19 in Italy, there was a reduction in the number of urgent cases, at the expense of an increase in severity, attributed to the delay in diagnosis ${ }^{10}$. Here in Brazil, despite the small number of cases, we managed to reach the same result in the evaluation of patients with AA, but not in cases of GBD, however, we can assume that in GBD there are more biases and that a larger study should be enlightening.

Contrary to the main findings in the literature, we found no difference in the incidence of perioperative complications, increased length of hospital stay, or mortality between uncomplicated and complicated AA. Regarding GBD, our data are consistent with those in the literature, maintaining the pattern of early treatment and treatment results.

\section{CONCLUSIONS}

In this paper, it was possible to identify the increase in the severity of presentation of AA occurrences during COVID-19. However, the same effect was not observed in GBD. Despite these findings in patients with $\mathrm{AA}$, the repercussions were not harmful to the patients and the outcomes were similar to the previous year.

This study was carried out in a university hospital in the south of Brazil that is renowned for treating COVID-19 patients. The study shows a short period of observation because we selected the moment of greatest restriction and social isolation. Possibly the data found here were influenced by this factor and to circumvent this bias larger and multicenter studies are necessary.

The small number of patients in this study increases the chance of type two error for most of our results and there is a risk of some patients who underwent cholecystectomy due to cholelithiasis has been included in our sample. Further studies and larger samples are required to understand better the impact of the COVID-19 worldwide.

\section{AUTHORS' CONTRIBUTIONS}

RPS: Data Curation, Methodology, Project Administration, Supervision, Writing - Original Draft. TLC: Data Curation, Formal Analysis, Methodology. AGT: Formal analysis, Methodology, Visualization, Writing - Original Draft. SB: Data Curation, Investigation. ECK: Data Curation, Investigation. JARP: Data Curation, Investigation. CG: Data Curation, Investigation. DCT: Data Curation, Investigation. VVD: Methodology, Writing - Original Draft, Writing - Review \& Editing. LTC: Conceptualization, Supervision, Writing Review \& Editing 


\section{REFERENCES}

1. Romero J, Valencia S, Guerrero A. Acute appendicitis during coronavirus disease 2019 (COVID-19): changes in clinical presentation and CT findings. J Am Coll Radiol. 2020;17(8):1011-3. https://doi.org/10.1016/j.jacr.2020.06.002

2. Pedziwiatr $M$, Lasek $A$, Wysocki $M$, Mavrikis J, Mysliwiec $P$, Bobowicz M, et al. Complicated appendicitis: risk factors and outcomes of laparoscopic appendectomy - Polish laparoscopic appendectomy results from a multicenter, large-cohort study. Ulus Travma Acil Cerrahi Derg. 2019;25(2):129-36. https:// doi.org/10.5505/tjtes.2018.80103

3. Heaton KW, Braddon FE, Mountford RA, Hughes AO, Emmett PM. Symptomatic and silent gall stones in the community. Gut. 1991;32(3):316-20. https://doi.org/10.1136/gut.32.3.316

4. Friedman GD. Natural history of asymptomatic and symptomatic gallstones. Am J Surg. 1993;165(4):399-404. https://doi. org/10.1016/s0002-9610(05)80930-4

5. Gunasekaran G, Naik D, Gupta A, Bhandari V, Kuppusamy M, Kumar G, Chishi NS. Gallbladder perforation: a single center experience of 32 cases. Korean J Hepatobiliary Pancreat Surg. 2015;19(1):6-10. https://doi.org/10.14701/ kjhbps.2015.19.1.6

6. Kao LS, Ball CG, Chaudhury PK; for Members of the Evidence Based Reviews in Surgery Group. Evidence-based Reviews in Surgery: Early Cholecystectomy for Cholecystitis. Ann Surg. 2018;268(6):940-2. https://doi.org/10.1097/ SLA.0000000000002867

7. Javanmard-Emamghissi $\mathrm{H}$, Boyd-Carson $\mathrm{H}$, Hollyman $\mathrm{M}$, Doleman B, Adiamah A, Lund JN, et al. The management of adult appendicitis during the COVID-19 pandemic: an interim analysis of a UK cohort study. Tech Coloproctol. 2021;25(4):40111. https://doi.org/10.1007/s10151-020-02297-4

8. Addiss DG, Shaffer N, Fowler BS, Tauxe RV. The epidemiology of appendicitis and appendectomy in the United States. Am J Epidemiol. 1990;132(5):910-25. https://doi.org/10.1093/ oxfordjournals.aje.a115734

9. Lee W, Jang JY, Cho JK, Hong SC, Jeong CY. Does surgical difficulty relate to severity of acute cholecystitis? Validation of the parkland grading scale based on intraoperative findings. Am J Surg. 2020;219(4):637-41. https://doi.org/10.1016/j. amjsurg.2018.12.005

10. Andersen KG, Rambaut A, Lipkin WI, Holmes EC, Garry RF. The proximal origin of SARS-CoV-2. Nat Med. 2020;26(4):450-2. https://doi.org/10.1038/s41591-020-0820-9

11. Patriti A, Baiocchi GL, Catena F, Marini P, Catarci M, FACS on behalf of the Associazione Chirurghi Ospedalieri Italiani (ACOI). Emergency general surgery in Italy during the COVID-19 outbreak: first survey from the real life. World J Emerg Surg. 2020;15(1):36. https://doi.org/10.1186/s13017-020-00314-3

12. Ologun GO, Lovely R, Sultany M, Aman M. Retained Gallstone Presenting as Large Intra-abdominal Mass Four Years after Laparoscopic Cholecystectomy. Cureus. 2018;10(1):e2030. https://doi.org/10.7759/cureus.2030

13. Bickell NA, Aufses AH Jr, Rojas M, Bodian C. How time affects the risk of rupture in appendicitis. J Am Coll Surg. 2006;202(3):401-6. https://doi.org/10.1016/j.jamcollsurg.2005.11.016

14. GlobalSurg Collaborative. Mortality of emergency abdominal surgery in high-, middle- and low-income countries. Br J Surg. 2016;103(8):971-88. https://doi.org/10.1002/bjs.10151 